\title{
Relationship Between Fear of COVID-19, Psychopathology and Sociodemographic Variables in Malaysian Population
}

\author{
Mohd Amiruddin Mohd Kassim ${ }^{1} \cdot$ Nicholas Tze Ping Pang ${ }^{1} \cdot$ \\ Noor Hassline Mohamed ${ }^{1}$ - Assis Kamu ${ }^{1}$ • Chong Mun Ho ${ }^{1}$. Friska Ayu ${ }^{2}$ • \\ Syed Sharizman Syed Abdul Rahim ${ }^{1} \cdot$ Azizan Omar $^{1} \cdot$ Mohammad Saffree Jeffree $^{1}$
}

Accepted: 13 November 2020 /Published online: 7 January 2021

(C) Springer Science+Business Media, LLC, part of Springer Nature 2021

\begin{abstract}
COVID-19 has affected Malaysia in multitude aspects. Although Malaysia is on the right track to flatten the curve attributed to swift and decisive actions by the government, it is important to assess the psychological after effect that caused by the pandemic and the movement control order. This study performed in Borneo, Malaysia, was conducted using principles of snowballing, and by invitation through university students and staffs mailing list to participate. The survey collected data on sociodemographic, along with measuring psychological impact by using the newly validated Malay version Fear of COVID-19 Scale and DASS-21 scale. There were a total of 255 respondents. The majority of the respondents' age was 25 years and below, with a female male ratio of 2:1 and around $70 \%$ respondents were students. Below 25-year-old age group, and females are having significantly higher levels of fear of COVID-19, depression, anxiety, and stress. Single people have higher depression level. There was a significant difference between students and non-students for depression, anxiety, and stress, but not for fear of COVID-19. It is imperative to allay the fears and psychological sequalae of COVID-19, especially those individuals at higher risks. Psychological interventions as well as telepsychiatry mobilisation could prove useful in dealing with the distress.
\end{abstract}

Keywords Malaysia $\cdot$ COVID-19 $\cdot$ Fear of COVID-19 Scale $\cdot$ Anxiety $\cdot$ Depression · Stress

COVID-19 has changed the whole perspective of year 2020 throughout the whole world, affecting various sectors and industries, such as health, education, finance, and manufacturing.

Nicholas Tze Ping Pang

nicholas@ums.edu.my

1 Faculty of Medicine and Health Science, Universiti Malaysia Sabah, Jalan UMS, 88400 Kota Kinabalu, Malaysia

2 Universitas Nahdlatul Ulama Surabaya, Surabaya, Indonesia 
In Malaysia, the first case of COVID-19 was detected on 24 January 2020, and since then, the number of cases steadily rose. Latest figures as of 9 July 2020 revealed 8683 total cases, total deaths of 121 , and a mortality rate of $1.4 \%$. The low mortality rate was contributed by swift and decisive action by the government of Malaysia; enacting movement control order (MCO) and closure of border, as well as aggressive contact tracing (Rahman 2020).

The MCO, which began on 18th March 2020 was done in phases. Phases 1-4, were strict lockdowns which lasted for almost 2 months, and were subsequently replaced by a conditional movement control order (CMCO) for 1 month, allowing few business sectors to operate. Due to local success in controlling the pandemic, the Malaysian government decided to implement the recovery movement control order (RMCO) until 31 August 2020, allowing most business sectors, government agencies, universities, and schools to open upon condition that social distancing and strict hygiene rules still applied.

Nevertheless, there has been a predicted "second wave" of mental health issues that may result from the aforementioned repercussions of the earlier MCOs. Despite efforts to implement new normal, the fear of the pandemic is still prevalent in society as there is uncertainty stemming from second waves all over the world as other countries attempt to either open up economic sectors or borders. There is no doubt Malaysians are still psychologically affected, whether by the pandemic itself or by the strict approach implemented by the government (Shanmugam et al. 2020). However, there is limited data that shows the reality of fear towards COVID-19 and attendant psychological distress that Malaysians are currently facing. The recently validated Malay version of Fear COVID-19 Scale was used together with the Depression, Anxiety and Stress scale in order to objectively and quantitatively assess the psychological aspect and assess relationships with relevant sociodemographic variables. This would allow quantitative data about the extent of all psychopathologies to be established, permitting identification of risk factors in a timelier manner, which in turns enable adequate attention and assistance to be delivered to the most psychologically affected parties.

\section{Method}

\section{Methodology}

This study was performed in predominantly university population in Borneo, Malaysia. Respondents were recruited through convenience sampling via a snowball method. In view of social distancing rules and to limit the risk of exposure, Google Form was utilised with the consent form, sociodemographic questionnaire, and both research scales in-built. Snowball recruitment was performed utilising student and staff mailing lists. A sample size of 200 was planned to be recruited. The data was collected from 25th May 2020 until 12th June 2020. Each participant was given a questionnaire containing three sections to fill in as follows.

Sociodemographic Questionnaire This was a simple questionnaire requesting for gender, education level, job, city the participant was currently living in during COVID-19, and marital status.

Fear of COVID-19 Scale The validated Malay version was administered. The Persian Fear of COVID-19 Scale consists of seven items (e.g. "I cannot sleep because I am worried about getting coronavirus-19”), scored on a five-item Likert point response ranging from 1 (strongly 
disagree) to 5 (strongly agree), and has English and Persian original versions. The possible scores range from 7 to 35 . The higher the score, the higher the level of fear of cororonavirus-19 (Ahorsu et al. 2020). The original Persian scale has good internal reliability (Cronbach alpha $=.82$ ) and test-retest reliability $(\mathrm{ICC}=.72)$, with satisfactory evaluations of other properties based on classical test theory and Rasch model analysis. The psychometric properties of the Malay FCV-19S is reasonable with a Cronbach alpha of 0.893 (Pang et al. 2020a, b, c).

DASS-21 Scale The DASS-21 (Lovibond and Lovibond 1995) is a self-report scale designed to measure the severity of emotional distress (depression and anxiety, and stress). It contains 21 items measuring three different domains: depression (e.g. "I couldn't seem to experience any positive feeling at all"), anxiety (e.g. "I was aware of dryness of my mouth"), and stress (e.g. "I found it hard to wind down"). Each item is rated on a four-point Likert scale ranging from 0 (did not apply to me at all over the last week) to 3 (applied to me very much or most of the time over the past week). Higher scores in each domain indicate greater severity of emotional distress in that domain. In the present study, the Malay version of the DASS-21 (Musa et al. 2007) was used to measure emotional distress in caregivers. The Malay validation demonstrated acceptable Cronbach's alpha values of .84, .74, and .79, respectively, for depression, anxiety, and stress. In addition, it had good factor loading values for most items (.39 to .73).

Data was analysed using SPSS 25 for Windows. Descriptive data was calculated for all sociodemographic variables and all four psychopathologies. Shapiro-Wilk tests assessed for normality of all continuous data. Relevant parametric or non-parametric tests were then performed to assess if there were significant differences for all four psychopathologies with respect to all sociodemographic variables. Correlations were also performed between all four psychopathologies for comparison with the similar correlations obtained in the validation study.

\section{Results}

As per Table 1, most of the respondents represented female students, under the age of 25, with a Bachelor's degree. The vast majority were not from Kota Kinabalu at the time of data collection, and were single.

Shapiro-Wilk tests for all variables measured (i.e. fear of COVID-19, depression, anxiety, and stress) suggested bivariate normality was violated, hence Spearman's correlation test was employed to test if there are significant correlations between the four variables. The results show that there were significant relationships between all four variables, namely fear of COVID-19-depression (Spearman's rho $=0.323, p<0.05$ ), fear of COVID-19-anxiety (Spearman's rho $=0.428, p<0.05$ ), fear of COVID-19-stress (Spearman's rho $=0.423, p<$ 0.05 ), depression-anxiety (Spearman's rho $=0.825, p<0.05$ ), depression-stress (Spearman's rho $=0.814, p<0.05$ ), and anxiety-stress (Spearman's rho $=0.856, p<0.05$ ).

Since the assumption of normality was violated, non-parametric tests which are KruskalWallis test and Mann-Whitney test were employed to test if there are significant differences in fear of COVID-19, depression, anxiety, and stress between age categories, gender, education levels, job status, areas, and marital status. The results show that the depression, anxiety, and stress were significantly different across age categories with the below 25-year-old age group 
Table 1 Background information of the respondents $(N=255)$

\begin{tabular}{llll}
\hline & & Count & $\%$ \\
\hline \multirow{2}{*}{ Age category } & & & $\%$ \\
& 25 years old and below & 144 & $56.5 \%$ \\
Gender & $26-35$ years old & 66 & $25.9 \%$ \\
& More than 35 years old & 45 & $17.6 \%$ \\
Education level & Female & $65.5 \%$ \\
& Male & 167 & $34.5 \%$ \\
& High school & 88 & $3.9 \%$ \\
& Diploma & 10 & $10.6 \%$ \\
Job status & Bachelor degree & 27 & $72.2 \%$ \\
& Master degree & $11.4 \%$ \\
City & Doctoral degree & 184 & $2.0 \%$ \\
& University staff & 29 & $20.4 \%$ \\
Marital status & Student & 5 & $69.4 \%$ \\
& Non university staff & 52 & $10.2 \%$ \\
& Kota Kinabalu & 177 & $30.6 \%$ \\
& Others & 26 & $69.4 \%$ \\
& Single & 78 & $70.6 \%$ \\
& Married & 177 & $27.1 \%$ \\
& Divorced & 180 & $2.4 \%$ \\
\hline
\end{tabular}

having significantly higher levels of depression, anxiety, and stress. But there was no significant difference in fear of COVID-19 between the three age categories (Table 2). As shown in Table 3, there was significant difference in fear of COVID-19, anxiety, and stress between male and female. There was no significant difference in all four variables across education levels. Students have higher level of depression and anxiety as compared to other job groups (Table 4). The study also found that the respondents who live in the area of Kota Kinabalu city (mean score $=18.56, \mathrm{SD}=5.84$ ) have lower fear of COVID-19 as compared to those who live in the other areas (mean score $=20.58, \mathrm{SD}=6.27)(Z=-2.673, p<0.05)$. The marital status has no effect on the variables except for the depression where the respondents with single status (mean score $=20.22, \mathrm{SD}=6.28$ ) having higher depression level as compared to the respondents with married (mean score $=19.49, \mathrm{SD}=5.78$ ) and also divorced status $($ mean score $=17.83, \mathrm{SD}=8.70)(H(2)=-13.304, p<0.017)$.

Table 2 Comparison of fear of COVID-19, depression, anxiety, and stress between age groups

\begin{tabular}{llllll}
\hline & Age category & $N$ & Mean & SD & Test statistics of Kruskal-Wallis test \\
\hline Fear of COVID-19 & 25 years old and below & 144 & 20.38 & 6.23 & $H(2)=6.983$ \\
& 26-35 years old & 66 & 20.30 & 6.00 & \\
Mepression & More than 35 years old & 45 & 18.16 & 6.21 & \\
& 25 years old and below & 144 & 4.84 & 4.91 & $H(2)=16.372^{*}$ \\
Anxiety & 26-35 years old & 66 & 2.91 & 3.80 & \\
& More than 35 years old & 45 & 2.58 & 3.80 & \\
Stress & 25 years old and below & 144 & 4.40 & 4.13 & $H(2)=12.005^{*}$ \\
& 26-35 years old & 66 & 3.33 & 3.65 & \\
& More than 35 years old & 45 & 2.53 & 3.94 & \\
& 25 years old and below & 144 & 5.49 & 4.48 & $H(2)=8.490^{*}$ \\
\hline
\end{tabular}

*The difference of score between groups is significant at 0.017 level of significance (adjusted based on the Bonferroni correction where 0.05 was divided by 3 ) 
Table 3 Comparison of fear of COVID-19, depression, anxiety, and stress between male and female

\begin{tabular}{llllll}
\hline & Gender & $N$ & Mean & SD & Test statistics of Mann-Whitney test \\
\hline Fear of COVID-19 & Female & 167 & 20.78 & 5.94 & $\mathrm{Z}=-3.006^{*}$ \\
& Male & 88 & 18.42 & 6.43 & \\
Depression & Female & 167 & 4.02 & 4.37 & $\mathrm{Z}=-1.444$ \\
\multirow{2}{*}{ Anxiety } & Male & 88 & 3.80 & 4.93 & \\
\multirow{2}{*}{ Stress } & Female & 167 & 4.02 & 3.83 & $Z=-2.227^{*}$ \\
& Male & 88 & 3.36 & 4.39 & \\
& Female & 167 & 5.26 & 4.21 & $Z=-2.736^{*}$ \\
\hline
\end{tabular}

*The difference of score between groups is significant at 0.05 level of significance

\section{Discussion}

The results of this study once again corroborate the findings of the initial validation study that suggest that the Fear of COVID-19 is correlated with anxiety, depression, and stress symptoms (Pang et al. 2020a). Although it appears that there might be higher rates of fear, depression, anxiety, and stress in older individuals, but when analysed by age group, it is interesting to observe the reverse conclusion being true - that there are significantly higher mean scores for all psychopathologies for younger age groups.

This can be related to multiple factors. There are most certainly psychological knock-on effects of COVID-19 on students. On a surface level, they are more cocooned from COVID19 's impact on the economy at large, as their livelihood is unaffected. This contrasts with the general public, who have clear and present fears about COVID-19, which relate to their employment, the prospects of closure and loss of livelihood for self-employed business owners, the stressors of childcare and total shutdown of schooling, and more fears about more severe health consequences of COVID-19, as research generally demonstrates that older people are more susceptible to the morbidity and mortality of COVID-19. There are most certainly behavioural changes in COVID-19, for instance hoarding and altruism, that can potentially explain a lot of human behaviour in the pandemic (Koh et al. 2020).

Table 4 Comparison of fear of COVID-19, depression, anxiety, and stress between job groups

\begin{tabular}{llllll}
\hline & Job status & $N$ & Mean & SD & Test statistics of Kruskal-Wallis test \\
\hline Fear of COVID-19 & University staff & 52 & 19.67 & 5.56 & $H(2)=.863$ \\
& Student & 177 & 20.10 & 6.27 & \\
& Non university staff & 26 & 19.65 & 7.09 & \\
Depression & University staff & 52 & 2.52 & 3.73 & $H(2)=15.875^{*}$ \\
& Student & 177 & 4.61 & 4.83 & \\
Anxiety & Non university staff & 26 & 2.23 & 2.92 & \\
& University staff & 52 & 2.87 & 3.55 & $H(2)=11.113^{*}$ \\
Stress & Student & 177 & 4.28 & 4.10 & \\
& Non university staff & 26 & 2.38 & 3.98 & \\
& University staff & 52 & 4.00 & 3.98 & $H(2)=6.722$ \\
& Student & 177 & 5.34 & 4.57 & \\
\hline
\end{tabular}

*The difference of score between groups is significant at 0.017 level of significance (adjusted based on the Bonferroni correction where 0.05 was divided by 3 ) 
The results from this study indicate that the difficulties faced by students due to COVID-19 may actually only represent the proverbial tip of an iceberg. Undergraduates no doubt face a multitude of challenges both from a mental health symptoms point of view, which includes current quarantine prospects, future employment uncertainties, and the effect on delayed study completion (Sahu 2020). Due to the sudden and dramatic nature of the Malaysian national lockdown, undergraduates living in-campus in Malaysian universities were forced to undergo an unexpected lockdown for over 2 months. Hence, the uncertainty stemming from the insecurity of knowing when the students are going to go home, the fear of isolation, and the fear of lack of support from university authorities were all factors that could have potentially increased the levels of the respective psychopathologies. Once again, the results suggest that being female and single are also risk factors for developing psychopathologies in the COVID19 pandemic. This correlates with similar findings from previous studies in the pandemic (Liu et al. 2012; Wang et al. 2020). Hence, it is important that these two risk factors are addressed by clinicians and university student affairs departments, and universal screening and treatment options offered.

Apart from that, the result of this study indicates that people living in urban area have lower fear of COVID-19 as compared to those in rural area. This could be attributed to better connectivity to regular updates and information regarding COVID-19, as well as close proximity to the hospital (Acuto 2020). On the other hand, the rural communities have poorer populations, poor access to COVID-19 information, and lesser hospital or medical facility as compared to urban area (Erwin et al. 2020; Smith and Trevelyn 2019; Summers-Gabr 2020). These limitations could be the contributing factors to higher level of fear of COVID-19 among those aforementioned communities.

There are multiple pathways for intervention that can be activated during the unique COVID-19 crisis, which call for creative solutions to age-old problems made complicated by social distancing rules and lockdowns. Telecounselling and telepsychiatry, previously much maligned due to the perceived efficacy of face to face interactions, have experienced a resurgence in the pandemic (Kannarkat et al. 2020). However, there are most certainly ethical and boundary issues surrounding these developments. Therefore, it is incumbent upon nation states and health authorities to jointly form steering committees to produce Standard Operating Procedures and fallback face to face alternatives for emergency situations. Counselling and psychology interventions can boost psychological mindedness, which have been shown in previous research to be efficacious as a partial mediator of the relationship between dysfunctional coping styles and depressive symptoms (Pang et al. 2020b). To combat the difficulties of having long psychotherapy protocols, obfuscating service delivery, there has been an ultrabrief psychological interventions module created in the midst of the COVID-19 crisis, that has been piloted amongst undergraduate students and frontline healthcare workers (Pang et al. 2020c). A timely and concise psychological intervention has been proven to be an effective tool in assisting those affected, and could be promoted as one of the important healthcare strategies in Malaysia's quest to strengthen its national resilience (Francis et al. 2020; Sulaiman et al. 2020).

This study does have certain limitations that preclude it from being fully generalisable to all strata of society. Due to its cross-sectional nature, only associational rather than causal linkages are able to be demonstrated. Moreover, it was done in a population that was largely university educated, hence there may be difficulties in extrapolating it to a general public with more secondary levels of education. Finally, it would have been helpful to look at mediational models had measurements of coping styles or psychological process variables been performed. 
Due to time constraints and the fact that students had already returned to their hometowns, it was crucial the authors captured the psychological zeitgeist of COVID-19 as swiftly as possible before a second wave of infection.

This is the first study to utilise the Fear of COVID-19 scale in Malay, and it again corroborates that the extant relationships between fear of COVID-19, depression, anxiety, and stress are present in larger magnitudes in a sample population that models the general population better than the predominantly undergraduate sample in the validation study. This study also provides preliminary evidence that magnitude of fears, worries, and stress is higher significantly in a university student group compared to a general public group. As students prepare to re-enter universities in stages in Malaysia beginning July 2020, it is imperative that a public health primary prevention approach, rather than a tertiary prevention approach to reduce the burden of pre-existing depression and anxiety, be deployed upon students' return. This will hopefully flatten the curve of the predicted second wave of increasing mental health illness and symptoms that pundits anticipate after the quelling of the physical pandemic.

\section{Conclusion}

In conclusion, this study illustrates the reality on mental health in a Malaysian university population which are affected directly or indirectly by COVID-19 pandemic. In this uncertain time, focus on health of Malaysians shall be equal, physical well-being, as well as mental health, to achieve more comprehensive coverage. Psychological interventions and online telepsychiatry should be strengthened as it could prove useful tools in managing the psychological distress.

\section{Compliance with Ethical Standards}

Conflict of Interest The authors declare that they have no conflict of interest. No funding was received for this study.

Informed Consent All procedures followed were in accordance with the ethical standards of the responsible committee on human experimentation (institutional and national) and with the Helsinki Declaration of 1975, as revised in 2000 (5). Informed consent was obtained from all patients for being included in the study.

Ethical Approval Ethical approval was obtained from the Universiti Malaysia Sabah Medical Research Ethics Committee (JKEtika 2/20 (2)) prior to commencement of this project. All participants provided informed consent.

\section{References}

Acuto, M. (2020). COVID-19: lessons for an urban(izing) world. One Earth, 2, 317-319. https://doi.org/10. 1016/j.oneear.2020.04.004.

Ahorsu, D. K., Lin, C. Y., Imani, V., Saffari, M., Griffiths, M. D., \& Pakpour, A. H. (2020). The fear of COVID19 scale: dDevelopment and initial validation. International Journal of Mental Health and Addiction. https:// doi.org/10.1007/s11469-020-00270-8.

Erwin, C., Aultman, J., Harter, T., Illes, J., \& Kogan, R. C. J. (2020). Rural and remote communities: unique ethical issues in the COVID-19 pandemic. American Journal of Bioethics, 20, 117-120. https://doi.org/10. $1080 / 15265161.2020 .1764139$. 
Francis, B., Juares Rizal, A., Ahmad Sabki, Z., \& Sulaiman, A. H. (2020). Remote psychological first aid (rPFA) in the time of Covid-19: a preliminary report of the Malaysian experience. Asian Journal of Psychiatry, 54, 102240. https://doi.org/10.1016/j.ajp.2020.102240.

Kannarkat, J. T., Smith, N. N., \& McLeod-Bryant, S. A. (2020). Mobilization of telepsychiatry in response to COVID-19-Moving toward 21st century access to care. Administration and Policy in Mental Health and Mental Health Services Research, 47, 489-491. https://doi.org/10.1007/s10488-020-01044-z.

Koh, E. B. Y., Pang, N. T. P., Shoesmith, W. D., James, S., Nor Hadi, N. M., \& Loo, J. L. (2020). The behaviour changes in response to COVID-19 pandemic within Malaysia. The Malaysian Journal of Medical Sciences, 27(2), 45-50.

Liu, X., Kakade, M., Fuller, C. J., Fan, B., Fang, Y., Kong, J., Guan, Z., \& Wu, P. (2012). Depression after exposure to stressful events: lessons learned from the severe acute respiratory syndrome epidemic. Comprehensive Psychiatry, 53, 15-23. https://doi.org/10.1016/j.comppsych.2011.02.003.

Lovibond, P., \& Lovibond, S. (1995). The structure of negative emotional states: comparison of the depression anxiety stress scales (DASS) with the Beck depression and anxiety inventories. Behaviour Research and Therapy, 33(3), 335-343. https://doi.org/10.1016/0005-7967(94)00075-U.

Musa, R., Fadzil, M. A., \& Zain, Z. (2007). Translation, validation and psychometric properties of Bahasa Malaysia version of the depression anxiety and stress scales (DASS). ASEAN Journal of Psychiatry, 8(2), 82-89.

Pang, N., Kamu, A., Hambali, N. L., Ho, C. M., Mohd Kassim, M. A., Mohamad, N. H., et al. (2020). Malay version of the fear of COVID-19 scale: validity and reliability. International Journal of Mental Health and Addiction. https://doi.org/10.1007/s11469-020-00355-4.

Pang, N. T. P., Masiran, R., Tan, K.-A., \& Kassim, A. (2020b). Psychological mindedness as a mediator in the relationship between dysfunctional coping styles and depressive symptoms in caregivers of children with autism spectrum disorder. Perspectives in Psychiatric Care. https://doi.org/10.1111/ppc.12481.

Pang, N. T. P., Shoesmith, W. D., James, S., Nor Hadi, N. M., Eugene Boon Yau, K., \& Loo, J. L. (2020c). Ultra brief psychological interventions for COVID-19 pandemic: introduction of a locally-adapted brief intervention for mental health and psychosocial support service. The Malaysian journal of Medical Sciences, 27(2), 51-56.

Rahman, F. (2020). The Malaysian response to COVID-19: building preparedness for 'Surge Capacity', testing efficiency, and containment. https:/kpkesihatan.com/2020/06/16/the-malaysian-response-to-covid-19building-preparedness-for-surge-capacity-testing-efficiency-and-containment/. Accessed 20 Aug 2020.

Sahu, P. (2020). Closure of universities due to coronavirus disease 2019 (COVID-19): impact on education and mental health of students and academic staff. Cureus. https://doi.org/10.7759/cureus.7541.

Shanmugam, H., Juhari, J. A., Nair, P., Chow, S. K., \& Ng, C. G. (2020). Impacts of COVID-19 pandemic on mental health in Malaysia: a single thread of hope. Malaysian Journal of Psychiatry 29(1).

Smith, A. S., \& Trevelyn, E. (2019). The older population in rural America: 2012-2016. United States Census Bureau.

Sulaiman, A. H., Ahmad Sabki, Z., Jaafa, M. J., Francis, B., Razali, K. A., Juares Rizal, A., Mokhtar, N. H., Juhari, J. A., Zainal, S., \& Ng, C. G. (2020). Development of a remote psychological first aid protocol for healthcare workers following the COVID-19 pandemic in a university teaching hospital, Malaysia. Healthcare, 8 . https://doi.org/10.3390/healthcare8030228.

Summers-Gabr, N. M. (2020). Rural-urban mental health disparities in the United States during COVID-19. Psychological Trauma, 12, S222-S224. https://doi.org/10.1037/tra0000871.

Wang, C., Pan, R., Wan, X., Tan, Y., Xu, L., Ho, C. S., \& Ho, R. C. (2020). Immediate psychological responses and associated factors during the initial stage of the 2019 coronavirus disease (COVID-19) epidemic among the general population in China. International Journal of Environmental Research and Public Health, 17. https://doi.org/10.3390/ijerph17051729.

Publisher's Note Springer Nature remains neutral with regard to jurisdictional claims in published maps and institutional affiliations. 